\title{
Su Peyzajı Projeleri, Kültür ve Doğayı Buluşturmak İçin Peyzaj Tasarımı ve Doğal Süreçleri Nasıl Bir Araya Getirir? Boston Park Sistemleri Örneği ve Güneş Şehir*
}

\author{
How do Waterscape Projects Combine Landscape Design and Natural Proceses to Create \\ Dialogues that Engage both Culture and Nature? The Case of the Boston Park System and \\ the Solar City
}

\author{
Aliki-Myrto PERYSINAKI \\ Çevirenler: Dicle OĞUZ ${ }^{1}$, Işıl ÇAKCI ${ }^{2}$ \\ ${ }^{1}$ Ankara Üniversitesi, Ziraat Fakültesi, Peyzaj Mimarlığı Bölümü, Ankara \\ ${ }^{2}$ Ankara Üniversitesi Çevre Sorunları Araştırma ve Uygulama Merkezi, Ankara
}

Özet: Doğanın kentsel gelişme sürecindeki dönüşümü, ekosistemin zarar görmesi ile sonuçlanmıştır. Doğal süreçleri içermek ve güçlendirmek için kurulan kentsel altyapı sonuçta bu süreçlere zarar vermiştir. Son yıllarda ekoloji ve kültür bilincine sahip tasarımcılar, insanlara doğayı ve mekanın kültürünü birarada sunan kentsel alanlar yaratmak üzere doğal süreçleri ve suyun estetik özelliklerini biraraya getirmeye çalışmaktadırlar. Bu tür projelere "su peyzajları" adı verilmiştir. Su peyzajları kamusal park ve meydanlarda inşaa edilmiş su elemanları olup; kent peyzajlarımızda suyun rolünü ortaya koyarak insanların suyun özelliklerini dokunma, görme ve ses yoluyla deneyimlemesine olanak sağlarlar. Su kaynaklarına bu şekilde yaklaşımın arkasındaki gerekçe insanların suyun güzellikleri ile ilişki kurabilecekleri sürdürülebilir ve güzel kentsel açık alanlar üretmektir.

Anahtar kelimeler: Su peyzajı, Ketsel ekoloji, Su altyapı sistemleri.

Abstract: The transformation of nature through urban development has resulted in a disturbed ecosystem. Urban infrastructure built to contain and overpower natural processes has finally been particularly harmful. In recent years, some ecologically and culturally conscious design practitioners have tried to develop a way to combine the processes of nature and the aesthetic qualities of water in order to create urban spaces that bring people together in embracing the nature and culture of a place. These types of projects are called "waterscapes." Waterscapes are constructed water features in urban public squares and parks: they celebrate the role of water in our urban landscapes and allow people to experience the qualities of water through touch, sight and sound. The rationale behind this way of treatment of water resources is to produce sustainable and beautiful urban spaces where people can engage with the pleasures of water.

Keywords: Waterscape, Urban ecology, Water infrastructure systems.

\section{Giriş}

Farklı uygarlıklarda su, daima peyzajı desteklemiştir. Dünyanın oluşumu ve dönüşümü su sayesindedir. Günümüzde kentsel alt yapı sistemleri ve peyzaj tasarımı ile ilgili etkileşimlere neden olan karmaşık kentsel gelişme süreçleri ile karşı karşıya bulunmaktayız. Su, çekici ve ferah bir alan yaratarak mekânsal kaliteyi iyileştirebilir.

Peyzaj mimarları, plancılar ve tasarımcılar peyzaj alanlarının dönüşümünde suyun önemini ve gücünü çok daha iyi bilmektedirler. Daha açık ifade edilirse, peyzaja karşı sorumluluklarımızı yeniden hatırlamamıza su neden olur. Kentsel formu şekillendirmek ve ekolojik ve estetik hedefleri karşılamak üzere oluşturulan günümüz su altyapı sistemlerinin potansiyelleri neredeyse kaybolmuştur. Aşırı ve tahmin edilemeyen kentsel gelişim süreçleri, mevcut su yaklaşımlarının işlevselliği ile ilgili büyük sorunlara neden olarak, yenilikçi çözüm talepleri doğurmaktadır.

\footnotetext{
* Perysinaki, A.M. 2010. How do Waterscape Projects Combine Landscape Design and Natural Proceses to Create Dialogues that Engage both Culture and Nature? The Case of the Boston Park System and the Solar City. World Wide Workshop for Young Environmental Scientists:2010, Arcueil, France.
} 
Su altyapı sistemlerinin ortaya çıkışı doğal fiziksel peyzaj yapısını daha da güçlendirerek, kültürel peyzajın yapılandırılması ve organize edilmesinde görsel ve mekânsal bir bileşen haline gelmiştir. Doğa ve insan arasındaki ilişkiler karmaşık süreçlerin çok iyi anlaşılmasını gerektirir. Su altyapısı sosyal ihtiyaçları karşılamak üzere açık alan ağı olarak hizmet ederek diğer önemli kentsel fonksiyonlarla sinerji yaratabilmekteydi. Ancak kentleşme nedeniyle artan baskı, yoğunluk ve hız, birçok kentte gözle görülebilir herhangi bir formdaki su altyapısının yok olmasına neden olmuştur.

Doğanın kentsel gelişme sürecindeki dönüşümü ekosistemin zarar görmesi ile sonuçlanmıştır. Zarar görmüş olan hidrolojik döngünün sonuçları arasında; kanalizasyon taşması ve kentsel yüzey akışı nedeniyle kirlenen suyolları, taban suyu seviyesindeki bozulmalara bağlı arazi çökmesi ve suyun temel hayat gücünü deneyimlemekten mahrum kalan kentliler yer almaktadır. Doğal süreçleri içermek ve güçlendirmek için kurulan kentsel altyapı sonuçta bu süreçlere zarar vermiştir. Bu gözlemler sonucunda suyun varlığının belirgin olacağı bir kentsel peyzaja sahip olabilmek için kentsel yapının yeniden incelenmesi gerektiğinin farkına varmalıyız.

Çağdaş peyzaj ve kent tasarımı kentsel peyzaja genellikle temelde manzara odaklı estetik düşüncelerle yaklaşmaktadır. Mevcut durumu değiştirmek ve daha çekici hale gelmek için birçok kent, kanal ve nehir kenarlarındaki kent içi alanlarını açmak üzere programlar geliştirmektedirler. Peyzaj mimarları ve tasarımcılar kendilerini altyapının teknik doğası konusunda sorgulamamaktalar. Bu alan daha çok mühendislere bırakılırken, peyzaj mimarlığı mesleğinin kentsel altyapı sistemlerinin yeniden kurulması ve geliştirilmesi konusunda lider bir rol üstlenmesi gerekmektedir. Peyzaj mimarlığının gücü; altyapı anlayışlarımızı doğal süreçleri, mühendislik ve kentsel tasarım stratejileri ile iliş̧kilendirecek biçimde genişletme yetisinde yatmaktadır. Su peyzajlarının altyapı sistemlerini yaratabilmek için, ekolojik sistemler konusunda daha derin ve pratik bilgiler ve farklı disiplinler arasında daha gelişmiş bir işbirliğinin geliştirilmesi temeldir.

Doğal ve yapısal olanın birleştirilmesi, sürdürülebilir kentsel ve bölgesel formun temeli olacak altyapı peyzajlarını oluşturmaya yönelik yeni fikirlerin doğmasını sağlayacaktır.

\section{Materyal ve Yöntem}

Sıv1 algısı (liquid perception) farklı bir algı durumunun ifadesidir. Sinema teorilerine göre, Gilles Deleuze, sıvı algısını "insan algısından daha güçlü, nesne gibi katı olmayan, durum veya ortam olarak düşünür. Daha nazik ve engin olan, moleküler bir algıdır" (Deleuze, 1986).

$\mathrm{Bu}$ çalışmada amaç, kentsel ekosistemi su-şehirciliği ile tanıştırarak, sistematik yaklaşıma yönelmenin önemini göstermektir. Sunulacak örnekler, suyun kent peyzajını nasıl şekillendirdiğini, projelerin nasıl suyun şehrin bölgeleri arasından hareketini insanların görmesine, duymasına ve deneyimlemesine izin verdiğini açık bir şekilde gösterecektir.

Son yıllarda ekoloji ve kültür bilincine sahip tasarımcılar, insanlara doğayı ve mekanın kültürünü birarada sunan kentsel alanlar yaratmak üzere doğal süreçleri ve suyun estetik özelliklerini biraraya getirmeye çalışmaktadırlar. Bu tür projelere "su peyzajları" adı verilmiştir. Su peyzajları kamusal park ve meydanlarda inşaa edilmiş su elemanları olup; kent peyzajlarımızda suyun rolünü ortaya koyarak insanların suyun özelliklerini dokunma, görme ve ses yoluyla deneyimlemesine olanak sağlarlar. Su kaynaklarına bu şekilde yaklaşımın arkasındaki gerekçe insanların suyun güzellikleri ile ilişki kurabilecekleri sürdürülebilir ve güzel kentsel açık alanlar üretmektir.

Çeşmeler ve açık su kanalları gibi su peyzajları, eski zamanlardan beri bilinen kentsel tasarımın su ile ne kadar yakından ilişkili olduğunu kanıtlayan örneklerdir. Bu ilişki antik çağlardan başlayarak orta çağa ve nihayetinde modern çağa kadar izlenebilmektedir. Su sadece şehrin zenginliği ile bağlantılı olmayıp aynı zamanda şehir ve çevresine ilişkin yaşayan bir ilişkiyi ifade etmek için de kullanılırdı.

Örneğin, küçük ölçekli bahçe veya park insan yapımı peyzajın en kapsamlı formudur. Bu form bize peyzajın nasıl çalıştığını anlamanın, su alanlarını daha karmaşık gereksinimlerle ekolojik koşullara ve topoğrafik ihtiyaçlara göre hayal edebilmenin yollarını gösterir. Ancak su ile ilgili olarak, kent ekosisteminin dengesini koruyarak, sürdürülebilir bir ilişkiye geçebilmek için halen cevaplanması gereken temel sorular mevcuttur. Sürdürülebilir su kültürüne doğru yönelmemiz gerekmektedir. Kentsel ekolojik su peyzajlarını oluşturabilmek için doğal su varlığı, estetik yaratımlar ile 
birleştirilmelidir: bilimsel olanın estetik ile birleştirilmesi suyun dönüşümüne ilişkin tasarım stratejilerini oluşturacaktır.

Bir peyzajın korunması ve yönetilmesi her peyzaj bileşeninin farkında olunmasını, korunmasını ve yönetilmesini gerektirmektedir. Su kaynakları peyzajı tamamlayan ve ekolojik çevrimi sağlayan en önemli doğal değerlerdir. Bu bağlamda:

i. Su kaynaklarının çeşitliliğinin estetik boyutu içererek algılanması ve suyun bir kaynak olarak tasarımda ve planlamada estetik boyutun da dahil edilerek ele alınması sürdürülebilirliğe katkıda bulunacaktır.

ii. Su kaynakları bir bütün olarak düşünülmeli ve tüm ilgili kültürel çalışmalar bu doğal değerleri gözeterek planlanmalı ve yönetilmelidir.

iii. Su makro düzeyde planlamada ve mikro düzeyde ise tasarım çalışmalarında görsel bir kaynak değeri olarak kullanılabilmelidir.

\section{3. Örnekler}

Bu çalışmada faklı dönemlerde yapılmış ve su ile ilgili prensiplerin öncelikler arasında olduğu sürdürülebilir kentleşme ilkelerini ortaya koyan iki örnek sunulacaktır.

\section{Boston Park Sistemi Back Bay Fens (Arka Körfez Bataklı̆̆)}

İlk örnek Frederick Law Olmsted tarafından tasarlanan Boston kenti park sistemidir. Frederick Law Olmsted, Amerikalı bir gazeteci, peyzaj tasarımcısı ve Amerikan peyzaj mimarlığının babasıdır. Central Park ve New York'taki Prospect Park gibi birçok iyi tanınan kent parkını tasarlayarak ün kazanmıştır. Kendi meslek alanında halen güçlü etkileri hissedilen bir peyzaj tasarım stili geliştirmiştir. Olmsted, kırsal, pitoresk peyzajın, kalabalık kentsel çevrenin sağlıksız sınırlamacı koşullarıla çelişerek buna zit hareket ettiğine ve toplumdaki tüm sınıfların pastoral deneyimi yaşayabilecekleri bir mekan sağlayarak toplumu güçlendirmeye hizmet ettiğine inanmıştır. "Eğlence alanlarını", sınırları boyunca geniş bitkilendirme ile gizleyerek, trafikten ayırarak ve kendi hedefleri ile uyumlu olmayan tüm kullanımları dışlayarak günlük yaşamın etkilerinden tamamen gizlemeye çalışmıştır.

Bununla birlikte, peyzajı kent nüfusunun çoğunun mümkün olduğunca çok yararlanabileceği yakınlığa taşımaya çalışmıştır. Her detayı belirli şekilde planlayan parklar ve kamusal rekrasyon alanları tasarlayarak, kullanıcılar üzerinde önemli psikolojik etkileri olan alanlar yaratmaya çalışmıştır. Ayrıca bütüncül park sistemleri ve belirli şehirleri yeşil alanlara bağlayan ekspres yollar tasarlamıştır.

$\mathrm{Bu}$ büyük ölçekli kent parklarının başarısı, kent formu konusunda yeni bir anlayışın uygulanmasını getirmiş ve sonuç olarak kent tasarımının diğer alanlarına da etki ederek, etik ve kente ait bir ideolojinin uygulamaya geçirilmesini sağlamıştır. Modern teknoloji ve bilim, bir kenti yaşamak için güvenli bir yer haline getirmiştir. Su ihtiyaçlarının karşılanmasındaki ilerlemeler, su arıtımı ve kanalizasyonla ilgili iyileştirmeler rahatlığı ve güvenliği artırarak şehirlerin sağlığına katkıda bulunmuştur.

19. yüzyılın sonları ve 20. yüzyılın başlarında, Frederick Law Olmsted hem karmaşık drenaj problemlerini çözmüş, hem de ve Back Bay Fens' deki (Şekil 1) gibi kamusal açık alanlar sağlamak üzere stratejiler geliştirmiştir. Metropolitan alan içerisinde manzaralı yollar ile birbirlerine bağlanmış park sistemlerine ilişkin düşüncelerinin en kapsamlı biçimi, 1890'larda sunduğu Boston Bölgesel Park Sistemi önerisinde yer almıştır. Günümüzde bu park sistemi, kentsel peyzajda doğalcılık yaklaşımının gelişiminin doruk noktası olarak kabul edilmektedir. Olmsted tarafından önerilen bu plan, yakın çevrede yer alan tuz bataklıklarının görünümünü akıllara getirmiştir. Bu alanı yönetebilmek için sağlık mühendisliği, trafik mühendisliği, rekreasyonel tesisler ve bilimsel eğitim kurumları ile ilgili sorunlara karşı ustaca çözümler geliştirmek zorunda kalmıştır.

Proje alanı (Back Bay Fens) zararlı, kanalizasyon karışan bir çamur alanıydı. Olmsted için projenin çözülmesi gereken güçlü bir sağlı tesisatı (altyapı tesisatı) yönü vardı. Alanda suyu sürekli tutabilmek için gelgit kapılı bir havza yarattı. Fens'i besleyen iki ana nehirin taşması durumunda havzada zararlanmalar ortaya çıkıyordu. Bu duruma çözüm olarak, taşkın süresince su baskınlarını önlemek için nehirleri normal akış hızında oluklarla Fens'e uğramadan geçirmeyi önerdi. Havza çevresinde kenarları hafifçe bitkilendirmek için iki problemi çözmesi gerekliydi. Öncelikle taşkın 
sularını tutmak için yeterli alan sağlamalı ve doğal gelişme için de yer kalmalıydı. İkinci olarak doğal kıyı çizgisini, fırtına sırasında dalgaların neden olduğu erozyondan korumalıydı. Önerisi kademeli setler yaratmak ve normal su düzeyinin hemen üzerinde bitkilendirilebilecek geniş adalar oluşturmaktı.

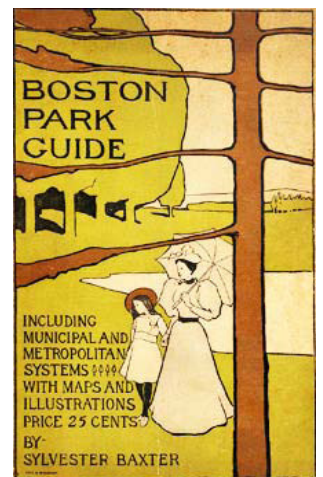

Şekil 1. Boston park rehberi, Sylvester baxter.

Bu proje, Back Bay ve Jamaica Gölü arasında Muddy Nehir vadisini ilişkilendirerek, Olmsted'e yapılı alanların ortasında nehir yollarının korunması olanağını vermiştir (Şekil2). Bazı yerlerde nehir vadisini daraltarak nehrin daha ince seyretmesini ve bir dizi pitoresk tatlı su göletleri oluşturulmasını önermiştir. Vadinin Boston tarafında, Back Bay tasarım sisteminde de devam eden bir yürüyüş, araba ve atla gezinti yolu sistemi planlamıştır. Diğer taraftan yürüyüş ve trafik yolları boyunca bitkilendirme için daha fazla alan ayırmıştır. Jamaica Gölü ve Franklin Parkı arasındaki yol, ağaçlıklı yollarla genişletilerek çok şeritli bir park yoluna dönüştürülmüştür.

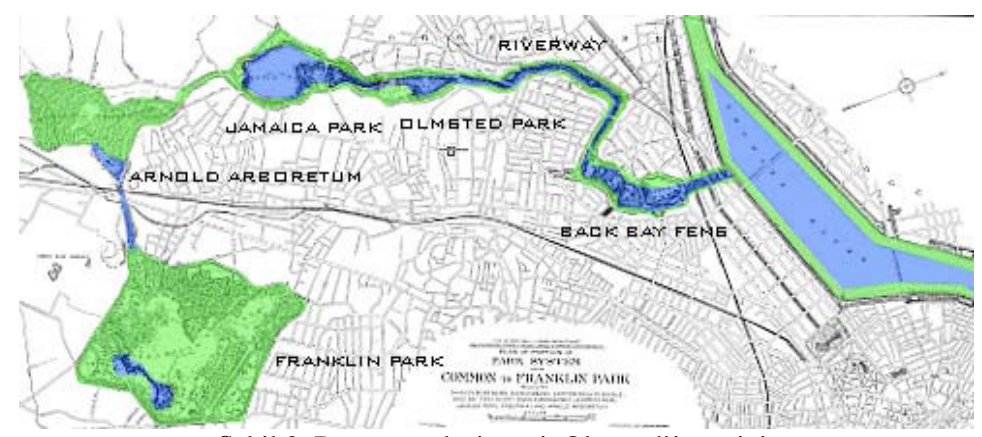

Şekil 2. Boston park sistemi, Olmsted'in arşivi.

"Zümrüt Kolye" (Emerald Necklace) olarak bilinen Olmsted'in planı, Boston park sistemi için park yolları olarak adlandırılan, ağaç sıralı yollarla birbirine bağlanan çeşitli küçük parklar içerir. Bu birbirinden ayrı ama birbirine bağlı park kavramı yaşayanlara bir yandan keyifli araba kullanma, piknik tempolu yürüyüş yapma gibi çeşitli rekreasyon biçimleri için yer sağlarken diğer taraftan da geleneksel kent merkezine yeni eklemlenen alanları bağlamanın bir yoludur (Şekil3).

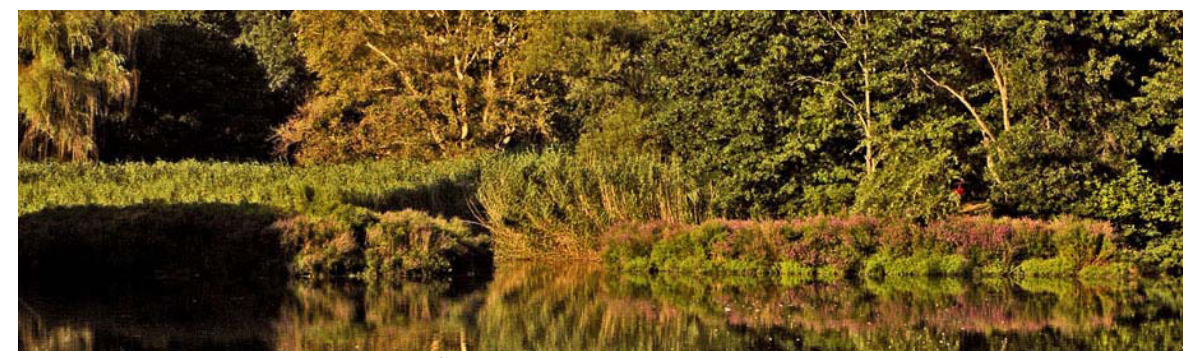

Şekil 3. Parktan bir görüntü. 


\section{Linz Güneş Şehri}

İkinci örnek Linz'deki (Avusturya) güneş şehridir. Linz güneş şehri projesi Linz eteklerinde 1300 haneyi barındıran bir güneş köyüdür. Linz Belediyesi, ilk 630 evin tasarlanması işini, 1970'lerden beri sürdürülebilir inşaatın öncülerinden Norman Foster, Richard Rogers ve Thomas Herzog'a vermiştir. Proje, sürdürülebilir mimari ilkelerine dayanarak yapılan en büyük yerleşim alanları arasındadır (Şekil 4). Projenin altında yatan temel ilke, düşük maliyetli inşaat yöntemlerini uluslar arası ölçekte yaygınlaştırma isteğidir. Sürdürülebilirlik göstergeleri, en yüksek olası yoğunluğa, modellerde azami esnekliğe ulaşılmasını ve yaya ile bisiklet trafiğini teşvik edecek ve hizmet verecek trafik güzergâhlarının dikkatle belirlenmesini içermektedir. Bireysel konutlar, seralar, kış bahçeleri ve balkonlarla birlikte, onları çevreleyen iklim ve doğadan yararlanarak konumlandırılarak, araziyle en uyumlu şekilde inşa edilmişlerdir. Göz önüne alınan önemli göstergelerden biri de enerji kaynaklarıdır. Köy, yalnızca kentin elektrik sistemi tarafından beslenmez, enerjisini gelecekte kendisini kentin sisteminden bağımsız kılacak ve hatta kendi enerjisinin bir kısmını şehir şebekesine aktaracak "solar" tesisler aracılığıyla üretir.

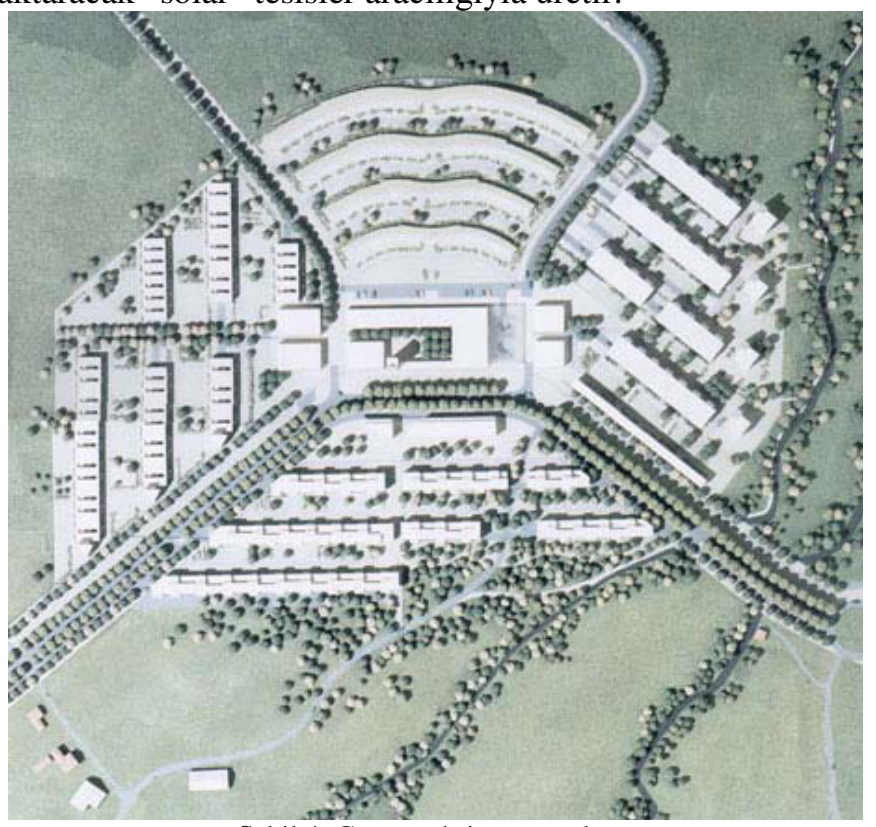

Şekil 4. Güneş şehri master planı.

Daha ayrıntılı olarak, alan, Linz'den geçen Tuna ve Traun nehirlerinin yakınında konumlanmıştır. Mekân, tipik sulak çayır peyzajı ile karakterize edilir. Amaç, bu sulak çayırları bir doğa koruma alanına dönüştürmekti. Bunun anlamı, tasarımcıların doğa koruma alanındaki tehlikeleri girişi yasaklayarak değil, kontrol ederek engellemeleri gerektiğiydi. Yağmur suyu kontrol edilmesi gereken ilk konuydu: yapıların yanından, ağaçlık çayırlara kadar uzanan bir kanallar, havzalar, göletler ve nehirler sistemi düşünülmüştü. Yağmur suyu, alandan süzülebileceği uygun yerlere taşınmıştır ve çok miktarda yağmur suyunun kendi kanalları vardır ya da güneş şehrinin kuzeyindeki su arkını beslemektedir.

Projenin öncelikleri arasında; yer altı suyunun iyileştirilmesi, geçici ve sürekli ıslak alanların oluşturulması ve en sonunda da nehir çayırlıklarındaki su rejiminin desteklenmesi yer almaktaydı. Peyzajı korumak için, güneş şehri ve doğa koruma alanı arasında oyun alanları, bahçeler ve toplanma alanları gibi bir dizi rekreasyon alanı kurulmuştur. Bunlara ek olarak, bir park koridoru ya da park yolu ve yüzülebilen gölet, hobi bahçeleri ve spor merkezi gibi kullanımlarla projenin zenginleştirilebileceği düşünülmüştür (Şekil 5 ve 6). 


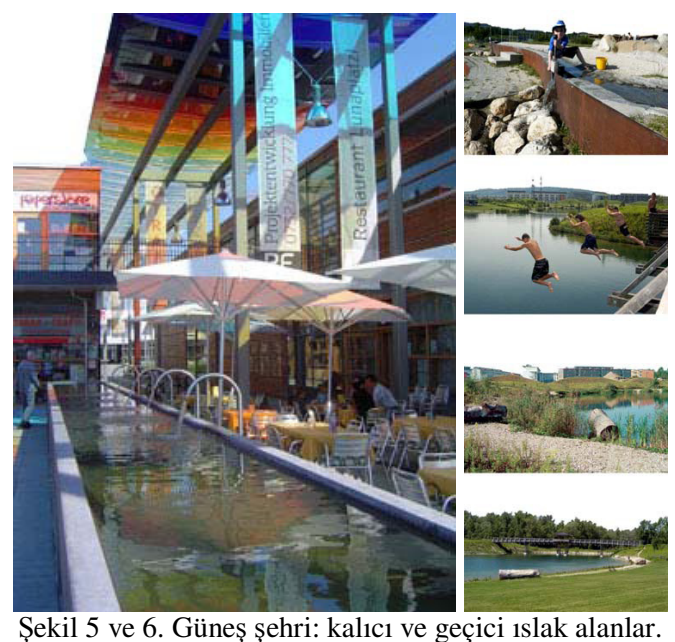

\section{Sonuç}

Kentsel altyapının bir parçası olarak su peyzajları, bir taraftan insanoğlu için suyun kültürel önemini ifade ederken, diğer taraftan doğadaki hidrolojik döngüyle uyum ve bütünlük içerisindedir. Su peyzajları, küçükten büyüğe tüm su elemanlarının inşasını ve onarımını kapsar ve bir alanın peyzaj tasarımında su elemanlarının ve yollarının kullanılmasına yoğunlaşır. Bu alanlar kentsel formu şekillendirmek için kullanılan, kentin içine nüfuz eden doğal elemanlar (nehirler, göller ya da denizler) olabildiği gibi, genellikle yapay yaratımlar da olabilirler. Havuzlar, şelaleler ve su elemanları, bir ofisi, peyzajı, eğlence alanını ya da odak noktasını tamamlamak üzere eklenebilirler. Doğal ve yapay su elemanları birlikte de kullanılabilir. Her iki durumda da dinamik doğal süreçlerden yararlanılması durumunda, tasarlanmış kentsel ekolojiler, yapay ekolojiler gibi görev göreceklerdir.

Tasarımcıların en değerli katkısı, bir projenin ilk aşamasında, teknik bakış açısıyla ve mekânların tasarımı, organizasyonu ve kullanımı için yaratıcı fikirler üretmekle olabilir. İlk etapta bütün olarak projenin konseptinin kavranması ve sonrasında detaylı tasarım çizimleri ve teknik şartnamenin temellerini alacağı master planın hazırlanması gerekir. Tasarımcılar aynı zamanda uygulama çalışmaları için sözleşme önerilerini onaylamak ve yön göstermek üzere gözden geçirebilirler. Tasarımcıların konu ile ilgili diğer becerileri ise tasarım etki değerlendirmelerinin hazırlanması, çevresel değerlendirmelerin yönetilmesi ve denetlemeler ile alan kullanım sorunlarında uzman bilirkişi olarak hizmet etmektir. Sonuç olarak su dikkatli yönetimi gerektiren doğal bir elemandır. Dikkatli depolama, temizleme, kullanım ve yeniden kullanım ile kentsel çevreler için yaşamsal bir eleman olarak (yeniden) düşünülebilir.

\section{Kaynaklar}

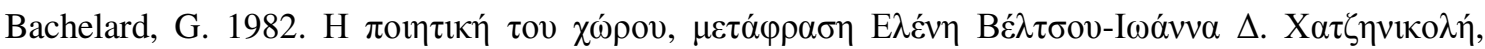

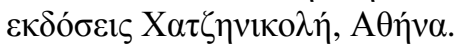

Baviskar, A. 2007. Waterscapes: The Cultural Politics of Natural Resource, Permanent Black, New Delhi.

Beveridge, C. E., Rocheleau, P. 1998. Frederick Law Olmsted, Designing the American landscape, Universe.

Dreiseitl, H., Grau, D., Ludwig, K.H.C. 2001. Waterscapes: Planning, Building and Designing with water, Birkhäuser, Basel.

Dreiseitl, H., Grau, D. 2009. Recent Waterscapes: Planning, Building and Designing with water, Birkhäuser, Basel.

France, R.L. 2002. Handbook of Water Sensitive Planning and Design (Integrative Studies in Water Management \& Land Deve), CRC Press. 
Galofaro, L. 2003. El arte como aproximación al paisaje contemporáneo, Art as an approach to contemporary landscape, Land\&Scaoe Series: Artscapes, GG, Editorial Gustavo Gili s.a., Barcelona.

Herzog, T. 2008. European Charter for Solar Energy in Architecture and Urban Planning, Prestel, USA.

Izembart, H., Le Boudec, B. 2003. Waterscapes: el tratamiento de aguas residuals mediante sistemas vegetales, G. Gilli, Barcelona.

Kuitert, W. 2008. Transforming with water. IFLA 2008 Proceedings of the 45th World Congress of the International Federation of Landscape Architects, Blauwdruk, Techne Press, Netherlands. Leblanc, L., Coulon, J. 1993. Paysages, Le Moniteur, Paris.

Norberg-Schulz, C. 1965. Intentions in Architecture. The MIT Press, Cambridge, Massachusetts, London.

Norberg-Schulz, C. 1980.Genius Loci, Towards a phenomenology of architecture. Academy editions, London.

Seamon, D., Mugerauer, R. 1985. Dwelling, place and environment: towards a phenomenology of person and world, Columbia University Press.

Treib, M. 1998. Modern landscape Architecture: A critical Review. The MIT Press, Cambridge, Massachusetts, London, England.

Zuaznabar, G. 2006. Piedra en el Paisaje. Cuadernos del Museo Oteiza 2, Fundación Museo Jorge Oteiza, Spain 2006. 